\title{
Multimorbidity and Decision-Making Preferences Among Older Adults
}

\author{
Winnie C. Chi, $\mathrm{PbD}^{1}$ \\ Jennifer Wolff, $\mathrm{PbD}^{2}$ \\ Raquel Greer, $M D, M H S^{3}$ \\ Sydney Dy, MD, MSc ${ }^{2}$ \\ 'RTI International, Washington, DC \\ ${ }^{2}$ Johns Hopkins University, Bloomberg \\ School of Public Health, Department of \\ Health Policy and Management, Baltimore, \\ Maryland \\ ${ }^{3}$ Johns Hopkins University School of Medi- \\ cine, Baltimore, Maryland
}

Conflicts of interest: authors report none.

\section{CORRESPONDING AUTHOR}

Winnie C. Chi, PhD

RTI International

701 13th St NW \#750

Washington, DC 20005

wchi@rti.org

\begin{abstract}
PURPOSE Understanding individuals' preferences for participating in health care decisions is foundational to delivering person-centered care. We aimed to (1) explore preferences for health care decision making among older adults, and (2) identify multimorbidity profiles associated with preferring less active, ie, passive, participation among older US adults.
\end{abstract}

METHOD Ours was a cross-sectional, nationally representative study of 2,017 National Health and Aging Trends Study respondents. Passive decision-making preference was defined as preferring to leave decisions to physicians. Multimorbidity profiles, based on 13 prevalent chronic conditions, were examined as (1) presence of 2 or more conditions, (2) a simple conditions count, and (3) a condition clusters count. Multiple logistic regression was used with adjustment for age, sex, education, English proficiency, and mobility limitation.

RESULTS Most older adults preferred to participate actively in making health care decisions. Older adults with 4 or more conditions, however, and those with multiple condition clusters are relatively less likely to prefer active decision making.

CONCLUSIONS Primary care physicians should initiate a shared decision-making process with older adults with 4 or more conditions or multiple condition clusters. Physicians should anticipate variation in decision-making preferences among older adults and adapt a decision-making process that suits individuals' preferences for participation to ensure person-centered care delivery.

Ann Fam Med 2017;15:546-551. https://doi.org/10.1370/afm.2106.

\section{INTRODUCTION}

$\mathrm{P}$ roviding person-centered care, which reflects an individual's preferences and health outcomes goals, is central to the management of individuals with multimorbidity, given the variation in the patterns of coexisting conditions and the lack of empirical evidence-based guidelines. ${ }^{1-4}$ Shared decision making is a useful strategy to operationalize person-centeredness, seeking to align physician-patient communication with individuals' preferences, values, and goals through a process of information exchange, joint consensus building, and agreement on treatment choice. ${ }^{5}$ Some studies have found that shared decision making is associated with better health outcomes, greater patient satisfaction, ${ }^{6}$ and reduced health care costs. ${ }^{7,8}$ Putting shared decision making in practice, however, could be challenging because it is an iterative dynamic process that requires participation from both patient and physician.

Understanding the relationship between multimorbidity and individuals' decision-making preferences is particularly important, given the inherent complexity of shared decision making and the increasing attention it is receiving from payers, regulatory agencies, and other stakeholders. ${ }^{9,10}$ Variation in decision-making preferences among older adults with multimorbidity, however, is largely unknown. Previous studies indicate that preference for active participation in health care decisions declines with an increasing number of chronic conditions among older adults. ${ }^{11}$ This relationship, however, may be more nuanced; certain conditions may exert 
greater influence and interact with other conditions in shaping decision-making preferences. ${ }^{12-16}$ Our study therefore aimed to (1) explore preferences for health care decision making among older adults, and (2) identify multimorbidity profiles associated with preferring less active participation among older US adults.

\section{METHODS}

Our retrospective cross-sectional study used data collected in 2012 from the National Health and Aging Trends Study (NHATS), a US population-based longitudinal study of older adults. The NHATS study design and procedures have been described previously. ${ }^{17}$ This study sample included a random sample of 2,017 older adults living in community settings who completed the health care decision-making module. We excluded participants with missing responses to the module $(\mathrm{n}=24)$ and nursing home participants $(\mathrm{n}=22)$. With sample weights, the study sample represented approximately 33.0 million Medicare beneficiaries aged 65 years and older in the United States. This study used public use files, and it was exempted from the Johns Hopkins School of Public Health Institutional Review Board review.

\section{Dependent Variables}

Survey respondents were asked their preferences for making health care decisions with doctors using a standardized question derived from existing empirical measures (Supplemental Appendix 1, available at http://www.annfammed.org/content/15/6/546/suppl/ DC1/). ${ }^{11,14,16}$ In the preliminary analyses, we found that older adults who preferred making decisions alone shared similar characteristics with older adults who preferred making decisions with doctors. We therefore categorized preferences into 2 distinct roles: (1) active role, in which individuals make decisions alone or together with their physician; and (2) passive role, in which individuals leave decisions to their physician. ${ }^{5,18}$

\section{Independent Variables}

We examined multimorbidity profiles in 3 ways to reflect various multimorbidity measures. ${ }^{1}$ We included 13 conditions: heart attack, heart diseases, hypertension, arthritis, osteoporosis, diabetes, lung disease, stroke, cancer, vision and hearing impairment, depression, and dementia (further description in Supplemental Appendix 2, available at http://www.annfammed. org/content/15/6/546/suppl/DC1/). ${ }^{19}$ First, we used the presence of multimorbidity, defined as having 2 or more chronic conditions. ${ }^{20}$ Second, we used a simple chronic conditions count, a commonly used approach. ${ }^{21}$ Third, we used a count of related condition clusters to address the limitation that a simple conditions count is sensitive to the number of conditions included (eg, study participants are likely to receive higher condition counts on average when a study includes more conditions). We included (1) cardiopulmonary, (2) sensory-motor, (3) depression-dementia, (4) arthritis-osteoporosis, and (5) cancer clusters (Supplemental Appendix 2), ${ }^{22}$ because these sets of clusters exhibited good predictability to future health outcomes. ${ }^{23-25}$

\section{Analysis}

We conducted simple logistic regression models for bivariate analysis and 3 parallel multiple logistic regression models (ie, 1 for each type of multimorbidity profiles) to examine the relationship between multimorbidity profiles and passive role preferences. Using backward elimination process, we included age, sex, educational attainment, English proficiency, and mobility limitation in multiple regression models. We conducted analyses in Stata SE 11 (StataCorp LP) using svy commands with analytical weight adjustment and a significance level of $\alpha=.05$.

\section{RESULTS}

Approximately 1 in every 7 older adults living in community settings responded that they prefer to leave health care decisions to their physicians, ie, a passive role, (14.9\%, 4.9 million). Older age, lower education, lower English proficiency, and limited mobility among older adults were associated with a passive role preference in health care decision making (Table 1).

Of the older adults, $18.9 \%$ with multimorbidity indicated that they preferred a passive role, which was more than twice the odds of those that did not have multimorbidity $(8.9 \%, \mathrm{OR}=2.35, P<.01)$ (Table 2 , unadjusted odds ratios). The odds of preferring a passive role in decision making varied by multimorbidity measures (Table 2, unadjusted odds ratios). The proportion of older adults who preferred a passive role was higher among those with 3 or more conditions and those with multiple condition clusters. Results from our multiple regression models were generally consistent with findings from simple regression models. Having 4 or more conditions and multiple condition clusters were associated with preferring a passive role (Table 2, adjusted odds ratios).

\section{DISCUSSION}

Using data from a representative survey on older adults in the United States, we found that most older adults preferred to participate actively in making 
Table 1. Characteristics Associated With Active and Passive Decision-Making Preferences

\begin{tabular}{|c|c|c|c|c|c|}
\hline Characteristic & $\begin{array}{c}\text { All } \\
\text { Column \% }\end{array}$ & $\begin{array}{l}\text { Active } \\
\text { Row \% }\end{array}$ & $\begin{array}{l}\text { Passive } \\
\text { Row \% }\end{array}$ & $\begin{array}{c}\text { Passive } \\
\text { OR }(95 \% \mathrm{Cl})\end{array}$ & $P$ Value \\
\hline \multicolumn{6}{|l|}{ Age, y } \\
\hline $65-74$ & 54.4 & 86.2 & 13.8 & 1 [Reference] & $\ldots$ \\
\hline $75-84$ & 33.4 & 82.7 & 17.3 & $1.29(0.91-1.84)$ & .15 \\
\hline$\geq 85$ & 12.2 & 71.8 & 28.2 & $2.39(1.65-3.47)$ & $<.01$ \\
\hline \multicolumn{6}{|l|}{ Sex } \\
\hline Female & 57.2 & 85.2 & 14.8 & 1 [Reference] & $\ldots$ \\
\hline Male & 42.8 & 80.8 & 19.2 & $1.35(0.98-1.85)$ & .06 \\
\hline \multicolumn{6}{|l|}{ Racelethnicity } \\
\hline White, non-Hispanic & 81.1 & 84.0 & 16.0 & 1 [Reference] & $\ldots$ \\
\hline Black, non-Hispanic & 8.1 & 79.8 & 20.2 & $1.32(0.91-1.92)$ & .14 \\
\hline Hispanic & 6.1 & 86.3 & 13.7 & $0.84(0.42-1.67)$ & .61 \\
\hline Others & 4.7 & 73.0 & 27.0 & $1.92(0.90-4.08)$ & .09 \\
\hline \multicolumn{6}{|l|}{ Education } \\
\hline >High school diploma & 78.7 & 86.3 & 13.7 & 1 [Reference] & $\ldots$ \\
\hline$<$ High school & 21.3 & 72.0 & 28.0 & $2.40(1.72-3.36)$ & $<.01$ \\
\hline \multicolumn{6}{|l|}{ Annual household income } \\
\hline$\geq 300 \%$ of $\mathrm{FPL}$ & 33.6 & 88.6 & 11.4 & 1 [Reference] & $\ldots$ \\
\hline $200 \%$ to $299 \%$ of $\mathrm{FPL}$ & 23.2 & 83.1 & 16.9 & $1.56(1.06-2.28)$ & .02 \\
\hline $100 \%$ to $199 \%$ of FPL & 23.1 & 80.3 & 19.7 & $1.89(1.18-3.00)$ & $<.01$ \\
\hline$<100 \%$ of $\mathrm{FPL}$ & 20.1 & 78.0 & 22.0 & $2.16(1.47-3.17)$ & $<.01$ \\
\hline \multicolumn{6}{|l|}{ Marital status } \\
\hline Married or living with a partner & 57.4 & 85.9 & 14.1 & 1 [Reference] & $\ldots$ \\
\hline Widowed & 25.9 & 79.5 & 20.5 & $1.56(1.14-2.12)$ & $<.01$ \\
\hline Separated, divorced, never married & 16.7 & 80.3 & 19.7 & $1.48(0.99-2.19)$ & .05 \\
\hline \multicolumn{6}{|l|}{ Length of residence } \\
\hline US born & 89.5 & 83.6 & 16.4 & 1 [Reference] & $\ldots$ \\
\hline Move to US at age $<45 \mathrm{y}$ & 8.4 & 85.3 & 14.7 & $0.88(0.49-1.56)$ & .65 \\
\hline Move to US at age $\geq 45 \mathrm{y}$ & 2.1 & 64.2 & 35.8 & $2.7(1.78-6.79)$ & .04 \\
\hline \multicolumn{6}{|l|}{ English proficiency } \\
\hline Yes $^{\mathrm{a}}$ & 97.8 & 83.9 & 16.1 & 1 [Reference] & $\ldots$ \\
\hline $\mathrm{No}^{\mathrm{a}}$ & 2.2 & 56.0 & 44.0 & $4.02(1.51-10.66)$ & $<.01$ \\
\hline \multicolumn{6}{|l|}{ Functional status } \\
\hline No self-care limitation ${ }^{b}$ & 75.7 & 86.4 & 13.6 & 1 [Reference] & $\ldots$ \\
\hline Self-care limitation ${ }^{\mathrm{b}}$ & 24.3 & 73.6 & 26.4 & $2.23(1.61-3.09)$ & $<.01$ \\
\hline No mobility limitation ${ }^{b}$ & 70.8 & 87.4 & 12.6 & 1 [Reference] & \\
\hline Mobility limitation ${ }^{b}$ & 29.2 & 73.2 & 26.8 & $2.48(1.81-3.40)$ & $<.01$ \\
\hline No household limitationc & 65.7 & 87.5 & 12.5 & 1 [Reference] & \\
\hline Household activities limitationc & 34.3 & 75.2 & 24.8 & $2.27(1.79-2.88)$ & $<.01$ \\
\hline \multicolumn{6}{|l|}{ Physician relationship } \\
\hline No usual source of care & 4.3 & 88.0 & 12.0 & 1 [Reference] & $\ldots$ \\
\hline Have usual source of care & 95.7 & 83.1 & 16.9 & $1.52(0.74-3.10)$ & .25 \\
\hline Did not see usual source of care last year & 6.5 & 85.1 & 14.9 & 1 [Reference] & $\ldots$ \\
\hline Saw usual source of care last year & 93.5 & 83.2 & 16.8 & $1.15(0.57-2.33)$ & .70 \\
\hline No informal caregiver sit in medical visits & 64.6 & 86.3 & 13.7 & 1 [Reference] & $\ldots$ \\
\hline Informal caregiver sit in medical visit & 35.4 & 77.8 & 22.2 & $1.78(1.40-2.25)$ & $<.01$ \\
\hline
\end{tabular}

FPL $=2001$ Federal poverty level.

Note: Unweighted random sample of 2,017 respondents. All numbers in the table are weighted estimates and not adjusted for covariates. Odds ratio estimates and corresponding $P$ values were based on simple logistic regression models (ie, bivariate analyses) using svy command in Stata to adjust for sampling design.

a Survey respondents who spoke English only or who spoke English very well or well were considered as having English proficiency; those who spoke English not well or not at all were considered as not having English proficiency.

b Survey respondents were asked how often they perform self-care activities (eating, getting cleaned up, using toilet, and getting dressed) and mobility (getting inside, outside of house, and getting out of bed) without help in the last month. Survey respondents were considered to have limitation in self-care activities or mobility if they reported having problems performing at least 1 activity in self-care activities or mobility, respectively, without help of any person.

'Survey respondents also were asked whether they had help doing household activities including doing laundry, shopping, preparing hot meals, handling banking and bills, and tracking medications in the last month. Household activities limitation was identified if a respondent reported having difficulty doing at least 1 household activity independently or having someone to do for/with for at least 1 household activity because of health reasons. 
Table 2. Odds of Passive Decision-Making Preferences by Multimorbidity Profiles

\begin{tabular}{|c|c|c|c|c|c|c|}
\hline Characteristic & $\begin{array}{c}\text { Active } \\
\%\end{array}$ & $\begin{array}{l}\text { Passive } \\
\%\end{array}$ & $\begin{array}{c}\text { Passive } \\
\text { OR }(95 \% \mathrm{CI})\end{array}$ & $P$ Value & $\begin{array}{c}\text { Passive AOR } \\
(95 \% \mathrm{CI})\end{array}$ & $P$ Value \\
\hline No multimorbidity & 91.1 & 8.9 & 1 [Reference] & $\ldots$ & $\ldots$ & $\ldots$ \\
\hline Multimorbidity & 81.1 & 18.9 & $2.35(1.55-3.54)$ & $<.01$ & $1.77(1.15-2.71)$ & .01 \\
\hline \multicolumn{7}{|l|}{$\begin{array}{l}\text { Number of conditions } \\
\text { in categories }\end{array}$} \\
\hline$\leq 1$ & 91.1 & 8.9 & 1 [Reference] & $\ldots$ & $\ldots$ & $\ldots$ \\
\hline 2 & 88.3 & 11.7 & $1.35(0.75-2.41)$ & .31 & $1.31(0.72-2.37)$ & .37 \\
\hline 3 & 84.3 & 15.7 & $1.88(1.17-3.02)$ & .01 & $1.47(0.88-2.43)$ & .14 \\
\hline 4 & 75.5 & 24.5 & $3.23(1.97-5.28)$ & $<.01$ & $2.61(1.58-4.31)$ & $<.01$ \\
\hline$\geq 5$ & 73.9 & 26.1 & $3.51(2.26-5.44)$ & $<.01$ & $2.21(1.38-3.52)$ & $<.01$ \\
\hline \multicolumn{7}{|c|}{$\begin{array}{l}\text { Number of condition clus- } \\
\text { ters in categories }\end{array}$} \\
\hline$\leq 1$ & 90.3 & 9.7 & 1 [Reference] & $\ldots$ & $\ldots$ & $\ldots$ \\
\hline 2 & 84.4 & 15.6 & $1.71(1.26-2.33)$ & $<.01$ & $1.58(1.11-2.24)$ & .01 \\
\hline 3 & 77.5 & 22.5 & $2.65(1.85-3.79)$ & $<.01$ & $2.05(1.39-3.03)$ & $<.01$ \\
\hline$\geq 4$ & 70.4 & 29.6 & $3.81(2.45-5.93)$ & $<.01$ & $2.19(1.35-3.56)$ & $<.01$ \\
\hline \multicolumn{7}{|c|}{ AOR = adjusted odds ratio. } \\
\hline \multicolumn{7}{|c|}{$\begin{array}{l}\text { a Three parallel multiple logistic regression models were used, } 1 \text { for each of } 3 \text { multimorbidity profiles. } \\
\text { b Covariates adjusted in multiple regression models included age ( } \leq 85 \text { years as reference group), sex (female as reference group), educational attainment (high schoo } \\
\text { or higher as reference group), English proficiency (proficient in English as reference group), and mobility limitation (no mobility limitation as reference group). }\end{array}$} \\
\hline
\end{tabular}

health care decisions, a finding corresponding to the observed greater decision-making participation among older adults in the United States, ${ }_{1}^{26-28}$ and to the findings among older adults with at least 3 conditions in Sweden. ${ }^{29}$ Our finding is promising for physicians, especially those involved in innovative health care delivery models, because shared decision making is considered an integral component and often tied to financial incentives in many of these models. ${ }^{30}$ For example, engaging individuals and family to actively participate in shared decision making is identified as 1 of the core functions in the Comprehensive Primary Care Plus model. ${ }^{31}$

Older adults with 4 or more conditions, however, and those with multiple condition clusters were relatively less likely to prefer active decision making. Despite that a stated preference for less active participation may reflect underlying personal traits for some individuals, it may also reflect prior medical encounters and illness experiences. Potential reasons include patients who are less healthy and who may feel more dependent on their physicians, to whom they delegate decision-making power ${ }^{13,14,16}$; time constraints to address multiple conditions during a single visit, which creates a less friendly environment for shared decision making ${ }^{5,29,32}$; and competing demands in managing multiple conditions, which makes it harder for patients to gain expertise and confidence to actively participate in decision making. ${ }^{33-36}$

We also found that older age, male sex, lower edu- cation, lower English proficiency, and limited mobility were associated with a passive role preference in health care decision making regardless of multimorbidity. The findings on age, sex, educational attainment, and language barrier were consistent with those of previous studies in general, ${ }_{1}^{12,14,37-39}$ but the association between functional status and preferences for decision making was largely unknown. ${ }^{40}$ Older adults with mobility limitations are likely to have informal caregivers to transport them to obtain health care, and they may feel more dependent on trusted caregivers or physicians and thus wish to relinquish control to others. ${ }^{14}$

This study has several limitations. Because our analysis was based on secondary data, the validity partially depends on the structure of the survey questions and participant interpretation of the questions. Multimorbidity was determined by a limited number of self-reported diagnoses that are prevalent or have a considerable impact causing disability among older adults. The analysis uses a single question for decisionmaking preference, as it was designed to capture individuals' preferences for overall care. ${ }^{11}$ Given the cross-sectional design, this study cannot draw causal inferences and may reflect cohort effect.

Primary care physicians should initiate the shared decision-making process with older adults, especially those with 4 or more conditions or multiple condition clusters by inviting them to participate in decision making. Recognizing the variation in stated decisionmaking preferences, physicians should anticipate that 
some older adults may be reluctant to participate initially but will participate eventually, and some of them may still prefer having their physicians make decisions. For older adults who prefer less active participation, it would still be important to elicit their goals and outcome preferences to ensure the care plan is person-centered, even if physicians will be making paternalist decisions. ${ }^{41}$

Future research is needed to identify potential barriers and facilitators to individuals' involvement in decision making when confronting multiple conditions, and such information may guide physicians in choosing strategies to encourage individuals' active participation.

To read or post commentaries in response to this article, see it online at http://www.AnnFamMed.org/content/15/6/546.

Key words: multimorbidity; shared decision making; patient engagement; person-centered care

Submitted September 22, 2016; submitted, revised, February 15, 2017; accepted March 27, 2017.

Funding support: This study was supported by the Agency for Healthcare Research and Quality predoctoral institutional research training grant (T32) and the Barbara Starfield Scholarship from Johns Hopkins University to support her doctoral training and this dissertation work at Johns Hopkins University, Bloomberg School of Public Health, Department of Health Policy and Management.

Previous presentation: An earlier version of the manuscript was presented as a poster at the AcademyHealth Annual Research Meeting; June 26-28, 2016; Boston, Massachusetts.

Acknowledgments: Dr Christopher Beadles, MD, PhD, at RTI International, provided helpful insight.

Supplementary materials: Available at http://www. AnnFamMed. org/content/15/6/546/suppl/DC1/.

\section{References}

1. Fortin M, Soubhi H, Hudon C, Bayliss EA, van den Akker M. Multimorbidity's many challenges. BMJ. 2007;334(7602):1016-1017.

2. Boyd CM, Fortin M. Future of multimorbidity research: how should understanding of multimorbidity inform health system design? Public Health Rev. 2010;32(2):451-474.

3. Tinetti ME, Fried TR, Boyd CM. Designing health care for the most common chronic condition-multimorbidity. JAMA. 2012;307(23): 2493-2494.

4. Muth C, van den Akker M, Blom JW, et al. The Ariadne principles: how to handle multimorbidity in primary care consultations. BMC Med. 2014;12(1):223-233.

5. Charles C, Gafni A, Whelan T. Shared decision-making in the medical encounter: what does it mean? (or it takes at least two to tango). Soc Sci Med. 1997;44(5):681-692.

6. Joosten EAG, DeFuentes-Merillas $L$, de Weert GH, Sensky T, van der Staak CPF, de Jong CAJ. Systematic review of the effects of shared decision-making on patient satisfaction, treatment adherence and health status. Psychother Psychosom. 2008;77(4):219-226.
7. O'Connor AM, Bennett CL, Stacey D, et al. Decision aids for people facing health treatment or screening decisions. Cochrane Database Syst Rev. 2009;(3):CD001431.

8. Arterburn D, Wellman R, Westbrook E, et al. Introducing decision aids at Group Health was linked to sharply lower hip and knee surgery rates and costs. Health Aff (Millwood). 2012;31(9):2094-2104.

9. Patient Protection and Affordable Care Act. 2010;3590 Public Law 111-148. Title IV, x4207, USC HR.

10. Oshima Lee E, Emanuel EJ. Shared decision making to improve care and reduce costs. N Engl J Med. 2013;368(1):6-8.

11. Wolff JL, Boyd CM. A look at person-centered and family-centered care among older adults: results from a national survey. [published correction appears in J Gen Intern Med. 2015;30(10):1567]. J Gen Intern Med. 2015;30(10):1497-1504.

12. Arora NK, McHorney CA. Patient preferences for medical decision making: who really wants to participate? Med Care. 2000;38(3): 335-341.

13. Benbassat J, Pilpel D, Tidhar M. Patients' preferences for participation in clinical decision making: a review of published surveys. Behav Med. 1998;24(2):81-88.

14. Levinson W, Kao A, Kuby A, Thisted RA. Not all patients want to participate in decision making. A national study of public preferences. J Gen Intern Med. 2005;20(6):531-535.

15. Murray E, Pollack L, White M, Lo B. Clinical decision-making: Patients' preferences and experiences. Patient Educ Couns. 2007; 65(2):189-196.

16. Zikmund-Fisher BJ, Couper MP, Singer E, et al. The DECISIONS study: a nationwide survey of United States adults regarding 9 common medical decisions. Med Decis Making. 2010;30(5)(Suppl): 20S-34S.

17. Kasper JD, Freedman VA. National Health and Aging Trends Study User Guide: Rounds 1 \& 2, Final Release. Baltimore, MD: John Hopkins University School of Public Health; 2014.

18. Roter DL, Stewart M, Putnam SM, Lipkin M Jr, Stiles W, Inui TS. Communication patterns of primary care physicians. JAMA. 1997; 277(4):350-356

19. Kasper JD, Freedman VA, Spillman BC. Classification of Persons by Dementia Status in the National Health and Aging Trends Study, Technical Paper \#5. Baltimore, MD: John Hopkins University School of Public Health;2013.

20. U.S. Department of Health \& Human Services. Multiple Chronic Conditions-A Strategic Framework: Optimum Health and Quality of Life for Individuals With Multiple Chronic Conditions. Washington, DC: US Department of Health and Human Services;2010.

21. Marengoni A, Angleman S, Melis R, et al. Aging with multimorbidity: a systematic review of the literature. Ageing Res Rev. 2011;10(4): 430-439.

22. John R, Kerby DS, Hennessy CH. Patterns and impact of comorbidity and multimorbidity among community-resident American Indian elders. Gerontologist. 2003;43(5):649-660.

23. Schäfer I, von Leitner E-C, Schön G, et al. Multimorbidity patterns in the elderly: a new approach of disease clustering identifies complex interrelations between chronic conditions. PloS One. 2010; 5(12):e15941.

24. Marengoni A, Rizzuto D, Wang HX, Winblad B, Fratiglioni L. Patterns of chronic multimorbidity in the elderly population. J Am Geriatr Soc. 2009;57(2):225-230.

25. Cornell JE, Pugh JA, Williams JW Jr, et al. Multimorbidity clusters: clustering binary data from multimorbidity clusters: clustering binary data from a large administrative medical database. Applied Multivariate Research. 2007;12(3):163-182.

26. Chewning B, Bylund CL, Shah B, Arora NK, Gueguen JA, Makoul G. Patient preferences for shared decisions: a systematic review. Patient Educ Couns. 2012;86(1):9-18. 
27. Belcher VN, Fried TR, Agostini JV, Tinetti ME. Views of older adults on patient participation in medication-related decision making. J Gen Intern Med. 2006;21(4):298-303.

28. Morton RL, Tong A, Howard K, Snelling P, Webster AC. The views of patients and carers in treatment decision making for chronic kidney disease: systematic review and thematic synthesis of qualitative studies. BMJ. 2010;340:c112.

29. Ekdahl AW, Andersson L, Wiréhn A-B, Friedrichsen M. Are elderly people with co-morbidities involved adequately in medical decision making when hospitalised? A cross-sectional survey. BMC Geriatr. 2011;11(1):46.

30. Fisher ES, McClellan MB, Safran DG. Building the path to accountable care. N Engl J Med. 2011;365(26):2445-2447.

31. Centers for M. Medicaid S. Comprehensive primary care initiative. https://innovation.cms.gov/initiatives/comprehensive-primary-careinitiative/. Published 2012. Accessed Dec 14, 2016.

32. Fung $\mathrm{CH}$, Setodji $\mathrm{CM}$, Kung F-Y, et al. The relationship between multimorbidity and patients' ratings of communication. J Gen Intern Med. 2008;23(6):788-793.

33. Kenny $P$, Quine $S$, Shiell A, Cameron S. Participation in treatment decision-making by women with early stage breast cancer. Health Expect. 1999;2(3):159-168.

34. Thorne SE, Paterson BL. Health care professional support for selfcare management in chronic illness: insights from diabetes research. Patient Educ Couns. 2001:42(1):81-90.
35. Piette JD, Kerr EA. The impact of comorbid chronic conditions on diabetes care. Diabetes Care. 2006;29(3):725-731.

36. Hibbard JH, Stockard J, Mahoney ER, Tusler M. Development of the Patient Activation Measure (PAM): conceptualizing and measuring activation in patients and consumers. Health Serv Res. 2004;39(4p1): 1005-1026.

37. Say R, Murtagh M, Thomson R. Patients' preference for involvement in medical decision making: a narrative review. Patient Educ Couns. 2006;60(2):102-114.

38. O' Donnell M, Monz B, Hunskaar S. General preferences for involvement in treatment decision making among European women with urinary incontinence. Soc Sci Med. 2007;64(9):1914-1924.

39. Florin J, Ehrenberg A, Ehnfors M. Clinical decision-making: predictors of patient participation in nursing care. J Clin Nurs. 2008;17(21): 2935-2944.

40. Elkin EB, Kim SHM, Casper ES, Kissane DW, Schrag D. Desire for information and involvement in treatment decisions: elderly cancer patients' preferences and their physicians' perceptions. J Clin Oncol. 2007;25(33):5275-5280.

41. Légaré $F$, Witteman HO. Shared decision making: examining key elements and barriers to adoption into routine clinical practice. Health Aff(Millwood). 2013;32(2):276-284. 